IRA-International Journal of Education \& Multidisciplinary Studies

ISSN 2455-2526; Vol.03, Issue 03 (2016)

Institute of Research Advances

http://research-advances.org/index.php/IJEMS

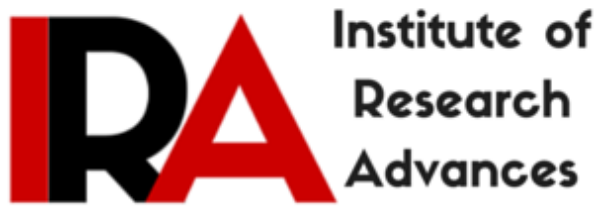

\title{
Inappropriateness in Iraqi EFL Learners' E-mail Requests to Professor
}

\section{${ }^{1}$ Shurooq Abboodi Ali}

School of Languages, Literacies, and Translation

Universiti Sains Malaysia.

\section{${ }^{2}$ Ambigapathy Pandian}

School of Languages, Literacies, and Translation

Universiti Sains Malaysia.

DOI: http://dx.doi.org/10.21013/jems.v3.n3.p13

\section{How to cite this paper:}

Abboodi Ali, S., \& Pandian, A. (2016). Inappropriateness in Iraqi EFL Learners' E-mail Requests to Professor. IRA International Journal of Education and Multidisciplinary Studies (ISSN 2455-2526), 3(3). doi:http://dx.doi.org/10.21013/jems.v3.n3.p13

(C) Institute of Research Advances

\section{(c) BY-NC}

This works is licensed under a Creative Commons Attribution-Non Commercial 4.0 International License subject to proper citation to the publication source of the work.

Disclaimer: The scholarly papers as reviewed and published by the Institute of Research Advances (IRA) are the views and opinions of their respective authors and are not the views or opinions of the IRA. The IRA disclaims of any harm or loss caused due to the published content to any party. 


\begin{abstract}
This study investigates the use of the speech act of request by Iraqi EFL (English as a foreign language) learners in student-professor e-mail communication. It aims to examine request strategies and internal modifications in academic requests in e-mail. There has been little investigation of the issue of an academic request made by Arab EFL learners to a higher status person via an authentic data. Thus, this study intends to provide more investigation of the strategies and internal modifiers that are produced by Iraqi EFL learners when they interact with their professors via e-mail. However, this study adapts the CCSARP (cross-cultural speech act realization project) originally suggested by [12] and modified by [8] in terms of strategies and internal modifications. Findings uncover that Iraqi EFL learners have a pragmatic problem when they issue their requests to a higher authority by e-mail. They mainly produce direct requests to higher status individuals. Such types of request require conventional indirectness to be appropriate pragmatically. These learners have limited pragmatic knowledge of conventional indirectness when they produce their requests to their professors. Moreover, Iraqi EFL learners are influenced by their L1 (first language) as they resort to direct substrategies that are customary forms in their Iraqi Arabic. This research unveils that Iraqi EFL learners have pragmalinguistic knowledge in syntactic downgraders and a pragmalinguistic deficiency in lexical devices due to the structurally oriented approach used to teach these learners.
\end{abstract}

Keywords: Academic request; authentic e-mail; appropriateness; strategies; internal modifications.

\title{
Introduction
}

The speech act of request has been widely investigated using either discourse completion tests $[11,20,16]$ or role play $[24,39]$. A request is a face-threatening act that conveys an imposition on the part of the hearer. Non-native speakers of English should be acquainted with L2 (second language) norms to produce L2 utterances properly. Arab EFL learners face great difficulty in expressing proper requests because they are not acquainted with the L2 cultural norms [1]. More specifically, Iraqi EFL learners have pragmatic infelicity because they produce inappropriate requests in the academic context when they interact with their professors by e-mail. E-mail is often used between student and professor in Iraq as the professor does not have sufficient time to see his/her student. As such, e-mail is used by the student to issue a request that is related to his/her research.

\section{Previous research}

Reference [12] designed the CCSARP coding scheme to examine the speech acts of request and apology among different languages. The CCSARP is deemed the most famous and distinguishing coding scheme in the field of cross-cultural pragmatics and ILP (interlanguage pragmatics) [6]. The CCSARP was employed by a number of researchers to examine the speech act of request using e-mail data. The CCSARP has been adapted by some researchers, primarily by [8] with respect to strategies and internal devices, to make it suitable for e-mail data.

Reference [22] was the initial study which analysed 99 authentic requests produced by native and non-native speakers of English via e-mail. The requests were assessed by professors to show whether they were positive or negative. The research showed a pragmatic deficiency by non-native speakers of English as they did not realize the imposition involved. Their requests lacked mitigated forms and focused on personal needs and unreasonable time-frames.

In a longitudinal study, [14] investigated 266 natural requests sent by an ESL (English as a second language) learner via e-mail in an American setting. A critical discourse analysis was used in the study. Findings uncovered that the learner faced difficulties in producing proper requests to a professor by e-mail. Chen's study also argued that her learner's behaviour developed when her knowledge and realization of L2 setting increased.

Reference [8] analysed 533 authentic requests sent by native and non-native speakers of English to professors by e-mail. Three types of request had been identified (appointment, feedback, and 
extension) and categorized to low, mid, and high imposition levels respectively. The original form of CCSARP by [12] had been adapted to fit the e-mail data. The study concluded that the participants were direct in appointment and feedback requests and conventionally indirect in extension requests which have the highest degree of imposition. It was also revealed that native speakers' requests were more polite than those of non-native speakers. Moreover, the requests were found to be heavily mitigated by syntactic downgraders, while lexical downgraders did not increase with increasing levels of imposition.

Reference [17] studied 200 natural requests produced by Greek EFL learners to professor via e-mail. Request strategies and lexical downgraders were examined. The CCSARP originally employed by [12] and later adapted by [8] was used. Requests are analysed in terms of low and high imposition levels. It was revealed that learners had pragmatic infelicities because they produced direct requests that lacked mitigation devices.

Reference [32] investigated 180 requests performed by Chinese learners of English and native speakers of English via elicited e-mails. CCSARP project of [12] had been modified and used in the Pan's study. The study concluded that Chinese learners of English showed fair control on pragmalinguistics but they had weaknesses in producing adequate syntactic downgraders. It was also revealed that learners overused the lexical downgraders and external modifiers in their requests.

In their study, [30] studied 20 requests sent by Arab ESL learners to their supervisors by authentic email in Malaysia. Reference [13] was utilized to analyse the politeness strategies while [12] was used to reveal the directness level. Reference [12] was utilized to examine the e-mail's construction. Reference [31] was employed to examine pragmatic transfer. It was revealed that Arab ESL learners were direct in their requests and misunderstanding occurred during communication with professor by e-mail.

The above-mentioned research has certain limitations. For instance, [30] investigated the politeness aspects based on [13]'s study, which does not apply to eastern culture. Thus, a number of scholars such as $[28,25]$ criticize [13]'s model of politeness because it is not universal for all cultures. Besides, pragmatic transfer is investigated in terms of one type of data. References [27,19] state that three types of data (L1, L2, and interlanguage) should be used for investigating pragmatic transfer. In this way the researcher can know exactly whether or not pragmatic transfer is evident.

A number of studies such as $[4,1,37]$ examined the speech act of request by Arab EFL/ESL learners using elicited data. Yet there has been very limited research into the speech act of request by Arab EFL learners via using natural data. Therefore, the current research fills the gap in ILP literature as it examines the speech act of request by Iraqi EFL learners when they issue their requests to their professors via e-mail in their Iraqi EFL setting. A survey of ILP literature shows that no similar research has been carried out so far. The current study aims to:

1. Examine the directness level that Iraqi EFL learners employ in requests when they interact with their professors by e-mail.

2. Examine the internal devices that Iraqi EFL learners employ in requests when they interact with their professors by e-mail.

\section{Methodology}

Two hundred e-mails are collected by 50 Iraqi EFL learners. These participants are undergraduates in the department of English, College of Arts, University of Baghdad. Their age ranges from 22 to 23. All of these learners are native speakers of Iraqi Arabic and are interested in the English language. Also, the e-mails of these respondents are related to issues in their academic research (e.g. requests for meetings or comments).

In order to avoid the drawbacks of the elicited data, the present study uses authentic data which is natural e-mails. Reference [7] argues a discourse completion task does not provide real utterances, 
genuine interaction, and accurate range of strategies. Besides, it does not show real occurrence in the performance act. In contrast, authentic data provides real utterances produced by subjects in genuine conditions [19]. Thus, natural e-mails are used in this research to examine genuine requests produced by Iraqi EFL learners.

Moreover, [15] states that small numbers of participants should be employed in qualitative research and uses a range of 1-40 respondents. In terms of [29], representativeness of data relies on the phenomenon one is examining, for the larger the disparity in the context of corpus under investigation, the more patterns and the larger corpus are needed to make certain of the data validity and representativeness. Contrariwise, On the other hand, one can argue that the more common the category being examined, the less data is needed. In addition, [21] emphasizes the saturation principle, where no more new points are revealed through analysing the data. Based on the aforementioned-discussion, 200 e-mails are considered representative enough of the act in question because the researcher arrives at data saturation.

The 200 e-mails are collected from three professors. The researcher has explained the aim of the present study to the professors, who have welcomed the investigation of their students' e-mails. They have supported the researcher in obtaining the corpus of e-mails by forwarding each e-mail to the researcher. The selection of e-mails is conducted purposely based on the research objectives. The data of e-mails are collected in 2015. A consent form is obtained from the professor and student. For examining the directness level and internal devices of request, the CCSARP coding scheme initially proposed by [12] and modified later by [8] is used in the current research. The CCSARP has been investigated cross-linguistically among diverse languages and used by a large number of scholars (such as, but not limited to, $[26,36,23,24,16,18,38,39,33,1,4]$ ). The CCSARP is also employed for investigating the e-mail data by a number of scholars; e.g. [22,8,17,32,30]. Thus, the universality of CCSARP and its successful application have been attested [5,41].

\section{Data analysis}

Mixed methods are employed to analyse the e-mail data. Qualitative analysis is used to identify the type of request strategy and syntactic modification. Discourse sequence is the unit of analysis. It is the sequence of utterances which involves request act realization. It includes the head act, which is the core element of request. The head act is divided into three levels of directness (direct, conventionally indirect, and nonconventionally indirect). Direct strategy involves mood derivables, explicit performatives, hedged performatives, locution derivables, direct questions, want statements, need statements, and expectation statements.

Conventional indirectness is divided into five categories in accordance with [12,8,23]. Reference [23] categorizes can/may I as a question about the requester's permission and can/may you as a question about the requestee's ability. As such, conventional indirectness involves: suggestory formulae, query preparatory/ability, query preparatory/permission, query preparatory/possibility, and query preparatory/willingness. The identification of permission and ability is confirmed by some scholars such as $[36,2]$ who state that the request form can/may I is correlated to the the requester's permission while the request type can/may you is related to the requestee's ability. Also, the former is related to the requester's oriented request while the latter refers to the requestee's oriented request [33]. An extra category (query preparatory/mitigated preparatory), which was not found in CCSARP before, ocurrs in the current data.

As for the nonconventionally indirect strategy, it comprises two categories: hints and nonverbal requests. The latter is a new category in the current data and it refers to wordless text (i.e. only attachment). Internal modifications encompass syntactic and lexical downgraders which also occur within the request head act to tone down the requestive force of the request. Syntactic downgraders comprise interrogative, conditional, tense, aspect, and embedding. Some syntactic downgraders have to be analysed with particular attention following the cautions presented by [12]. The interrogative in the form of preparatory strategy can/could I/you is not coded as a syntactic downgrader because it is unmarked. Also, the aspect marker is deemed a syntactic downgrader only in the case that it can be substituted by a simple form; e.g. I am wondering vs. I wonder. In addition, the past tense is coded as 
a syntactic mitigator only in the case that it can be employed with present time reference without varying the utterance's semantic meaning; e.g. I wanted to ask you... vs. I want to ask you.... Besides, the past tense modal has been included within the past tense form following the classification of [8]. Regarding lexical downgraders, four categories are involved: politeness marker, hedged downtoner, subjectivizer, and consultative device.

Moreover, quantitative analysis is implemented to uncover the number of request strategies and syntactic modifications, using percentages to show the amount of each request strategy and internal modification. For the purposes of consistency, three inter-raters are invited to check the coding scheme. The inter-raters are experts in pragmatics. They are professors in the University of Baghdad, Iraq and have ten years of experience in English language and linguistics. The reliability result is $85 \%$ among the inter-raters.

A point worth clarifying is that the researcher analyses internal modifications irrespective of strategy type adopting the trend of [17], who states that "the majority of existing studies on request modification have analysed modification irrespective of strategy". This is to better compare the results with previous research findings.

\section{Results and discussion}

\section{Request Strategies}

Table 1 reports the request super-strategies performed by Iraqi EFL learners in e-mail. On the whole, Iraqi EFL learners show a higher preference for direct strategies $(50 \%)$ than conventional strategies (29\%) and nonconventionally indirect strategies $(21 \%)$ in their requests. Iraqi EFL learners have displayed a pragmalinguistic deficiency because they use more direct strategy in requests that call for conventional indirectness. Reference [12] states that conventional indirectness is the most proper form in requesting because direct strategy implies disregard to face and nonconventional indirectness conveys regard to pragmatic opacity. References $[13,36]$ also emphasize that polite requests can be fulfilled using conventional indirectness.

However, the result of the present study is in line with previous research findings such as $[8,17,30,35]$, which showed that subjects preferred to be direct in their requests with higher-ups in email. Iraqi EFL learners' directness could be related to the notion of positive face. Iraq is a collectivistic culture that focuses on the positive politeness orientation and values in-group nexus and solidarity, which is opposite to western culture. Positive face and directness are concentrated on in collectivistic culture, unlike individualistic culture which focuses on negative face (indirectness) $[16,40]$.

Iraqi EFL learners have tended to be direct as they are influenced by their Iraqi Arabic. These learners have displayed a great preference for direct sub-strategies that are commonly used in Iraqi Arabic. Want statements and mood derivables are frequently used by these learners in e-mail, as shown in Table 2.

Below are some examples on direct sub-strategies written by Iraqi EFL learners in e-mail:

\section{Want statement:}

From: Learner's e-mail

Date: Fri, Jun 5, 2015 at 5:17 PM

Subject: this is my research

To: Professor's e-mail

Dear Dr. (X)

Please I want your notice on my research if you don't mind.

Rgds

Mood derivable:

From: Learner's e-mail 
Date: Wed, Jul 8, 2015 at 4:20 PM

Subject: your feedback

To: Professor's e-mail

My respectable doctor,

Please send me your feedback on my research if it suits you.

Yours,

Explicit Performative:

From: Learner's e-mail

Date: Thu, Jul 30, 2015 at 12:30 AM

Subject: my chapter

To: Professor's e-mail

Please I ask you to read my chapter if it is possible.

Thank you

Hedged performative:

From: Learner's e-mail

Date: Sat, Aug 1, 2015 at 8:10 PM

Subject: your feedback

To: Professor's e-mail

Dear Prof. (X)

If you don't mind, I would like you to read my chapter please.

Your student

Need statement:

From: Learner's e-mail

Date: Tue, May 5, 2015 at 9:30 PM

Subject: my section

To: Professor's e-mail

Dear Sir,

Please I need you to read section three. Regarding section four, I'm still writing on it.

Rgds,

Direct question:

From: Learner's e-mail

Date: Mon, Jun 22, 2015 at 5:40 PM

Subject:

To: Professor's e-mail

Dear Professor (X),

Do I need to add another paragraph? If so, please tell me.

Yours

Expectation statement:

From: Learner's e-mail

Date: Fri, Aug 7, 2015 at 8:19 PM

Subject: my chapter

To: Professor's e-mail

Dear Dr. (X)

I hope you will finish it by September ...

Best Regards

Locution derivable:

From: Learner's e-mail

Date: Sun, Sep 19, 2015 at 3:22 PM

Subject: another meeting

To: Professor's e-mail

I have to change the appointment to another date.

Yours,

It is clear that Iraqi EFL learners want to be explicit in their requests by being direct. They might reckon that they do not need to produce their requests indirectly as their requests are related to their 
academic research, which their professors are responsible for. They mainly use want statements because they want to be clear in expressing their wishes and desires in their requests to their professors. Reference [33] displays that the illocutionary intention of a want statement is clear and it is simple to deduce the proposed meaning behind it.

Yet, a want statement elevates the right of the requester and the obligation on the requestee when it is produced from a lower status person. It shows the requester's personal desires apart from the academic context. Thus, such requests are negative rather than positive [22]. In addition, a want statement has a coercive tone as it conveys no options other than replying [14].

Mood derivables are also preferred by Iraqi EFL learners in their requests. These learners use them to express their requests directly and rapidly, so the force of the request is very clear to the professor. As such, these learners elevate the requestive force of their requests. Iraqi EFL learners might reckon that they have the right to be peremptory because their requests pertain to their research and the professor has to reply. Mood derivable mirrors improper request because it involves a high tone of directness in its nature [33] and the student has no authority to use it with a professor [22]. It also implies a demand and an obligation on the professor [18].

Performatives are also implemented by Iraqi EFL learners. These learners want to produce explicit and clear requests to their professors, despite the fact that such requests are not preferred by learners of English with increasing pragmatic competence [33].

As for the hedged performative, it includes a syntactic downgrader (past tense modal) which makes the request more formal and rather acceptable as the tone of the request is mitigated. This is confirmed by [33] who clarified that the hedged performative is deemed more appropriate because the hedge softens the tone when it comprises a moderated verb before the performative verb. Iraqi EFL learners might acquire it via their academic attainment and ILP could have an effect on its use by these learners.

The other direct sub-strategies (need statement, direct question, and expectation statement) are only used to a limited extent by Iraqi EFL learners. This is due to the fact that these learners prefer to express their aims via want statements, mood derivables, and performatives. In addition, these learners have a low incidence of locution derivables. The underuse of locution derivables is evident in previous research, conducted by [33], and is due to their heterogeneous nature.

Moreover, conventionally indirect strategies are also used by Iraqi EFL learners but their occurrence is lower than that of direct strategies. Query preparatory/permission, query preparatory/ability, and query preparatory/mitigated preparatory are used more than the other types of conventionally indirect sub-strategies, as illustrated in Table 3.

Query preparatory/permission and query preparatory/ability are employed by Iraqi EFL learners to reduce the requestive force of their request. Iraqi EFL learners use the former to ask for permission to show more respect to the professor, while they use the latter to ask about the ability of the professor to grant them the request they want. The tone of the request could be modulated by such forms. Also, these forms are customary forms in Iraqi Arabic which shows that Iraqi EFL learners revert to their L1 to produce their requests in L2. Examples of query preparatory/permission and query preparatory/ability are presented below:

From: Learner's e-mail

Date: Sat, Jun 27, 2015 at 8:22 PM

Subject: meet you

To: Professor's e-mail

Can I meet you?

From: Learner's e-mail 
Date: Sun, May 30, 2015 at 12:19 AM

Subject: meeting

To: Professor's e-mail

Dear Sir,

Could you change the meeting to another day if you don't mind?

Iraqi EFL learners mitigate the threatening nature of their requests and maintain their professors' faces by employing softening forms which embedded the request act within routine formulas (i.e. query preparatory/mitigated preparatory) such as:

From: Learner's e-mail

Date: Tue, Aug 11, 2015 at 10:15 PM

Subject: Submission

To: Professor's e-mail

Dear Dr. (X),

I wonder if you can delay the submission of my paper to another date.

Thank you

From: Learner's e-mail

Date: Sun, Aug 15, 2015 at 2:10 PM

Subject: meeting

To: Professor's e-mail

Dear Ms. (X)

I wonder whether it is possible to set up a meeting with you this week.

Rgds,

Other types of conventional indirectness (query preparatory/willingness, query preparatory/possibility, and suggestory formulae) are used very sparingly as compared to query preparatory/permission, mitigated preparatory, and ability. Examples of willingness, possibility, and suggestory formulae are shown below:

Willingness:

From: Learner's e-mail

Date: Fri, Sep 25, 2015 at 9:30 PM

Subject:

To: Professor's e-mail

Dear Professor (X),

Would you send me your notices on chapter four? Thank you

Rgds,

Possibility:

From: Learner's e-mail

Date: Thu, Aug 27, 2015 at 7:44 PM

Subject: see u

To: Professor's e-mail

Dear Dr. (X)

Is it possible to see you next week.

With my respect

Suggestory formulae:

From: Learner's e-mail

Date: Sat, Aug 8, 2015 at 11:43 PM

Subject: my chapter

To: Professor's e-mail

I suggest we meet this week. 
Thank you

Furthermore, Iraqi EFL learners use nonconventionally indirect strategies less than any other strategies. Table 3 demonstrates that these learners use more hints than nonverbal requests. This is due to the fact that hints become formulaic expressions in e-mail and learners use them as the professor is familiar with it, presuming that the intended meaning is expressed by the context (cf. [8]). An example of hints is shown below:

From: Learner's e-mail

Date: Mon, Jul 13, 2015 at 5:19 PM

Subject: my proposal

To: Professor's e-mail

Dear Dr. (X)

Attached is my proposal.

Rgds,

\section{Request Syntactic Downgraders}

Iraqi EFL learners have used a range of syntactic downgraders to modulate the requestive tone of their requests as presented in Table 5 .

Conditional, embedding, and tense are the most common syntactic downgraders in requesting by Iraqi EFL learners overall. It seems that these learners tend to use more conditional forms as they are influenced by their L1. The conditional is widely used in Iraqi Arabic and individuals revert to it in requesting. It is easy for these learners to learn and thus they prefer to use it. Embedding is also used and occurs with reference to a conditional clause. In the present data, embedding includes appreciative and embedded forms which are used to decrease coerciveness in requesting. It is used to preface the request with a clause while the request is embedded within. Embedding is learnt by these learners via the structural approach. In addition, the learners use embedding because it becomes a mechanical and formulaic form in academic e-mail as underlined by [32], who reports that embedding has become a conventional form in academic requests by e-mail.

Past tense and past tense modal are also employed by Iraqi EFL learners to soften the threatening force of their requests. Such syntactic downgraders are easily learnt by these learners while they are learning English. As for interrogative and aspect, they are used sparingly as Iraqi EFL learners have more control in using conditional, embedding, and tense in requesting. In addition, aspect is absent in Iraq Arabic while it is available in English, as [3] confirms. There is evidence from previous research about the uncommon use of aspect in requesting, which is related to the point that learning to use aspect takes time [38]. Examples on syntactic downgraders can be displayed below:

Conditional:

From: Learner's e-mail

Date: Tue, Aug 27, 2015 at 1:33 PM

Subject: feedback

To: Professor's e-mail

Dear Professor (X)

Good morning

If you don't mind, send me your feedback and advices on my research by this week plz.

With many thanks

Embedding:

From: Learner's e-mail

Date: Mon, Aug 24, 2015 at 7:55 PM

Subject: meet u

To: Professor's e-mail

Dear Ms. (X)

I would be grateful if you can fix a meeting to see you.

Yours, 
Past Tense:

From: Learner's e-mail

Date: Sun, Sep 26, 2015 at 9:32 PM

Subject: ur opinion

To: Professor's e-mail

I wanted your opinion on my proposal please.

Cordially,

Interrogative:

From: Learner's e-mail

Date: Mon, Jul 6, 2015 at 4:56 PM

Subject:

To: Professor's e-mail

Would you give me your comments on my paper?

Aspect:

From: Learner's e-mail

Date: Tue, Jun 30, 2015 at 8:10 PM

Subject: my paper

To: Professor's e-mail

Dear Sir,

I'm kindly asking you to read my paper.

Rgds,

3. Request lexical downgraders

Iraqi EFL learners employ diverse lexical downgraders in requesting by e-mail, as reported in Table 6 . The politeness marker is the most prominent lexical downgrader, as compared to other lexical downgraders. Iraqi EFL learners have used it to reduce the force of their requests. It is clear that these learners have found the politeness marker easy to include in their requests. In this vein, [20] states that the politeness marker does not need a high degree of pragmalinguistic knowledge to be produced by learners and it has two functions: (i) an illocutionary force indicator and (ii) a clear mitigating device. Besides, [33] argues that the politeness marker is not difficult to integrate into a sentence.

Hedged downtoners, subjectivizers, and consultative devices are sparingly used as compared to politeness markers. This could be related to the fact that such lexical downgraders, other than politeness markers, require higher pragmalinguistic ability to be used in requesting. Iraqi EFL learners use a lower proportion of consultative devices than of other devices, which is related to the culture of Iraq. The culture of Iraq is a collectivistic culture that gives more focus on in-group relations, cordiality, and solidarity and consultative forms are not operative within it. In a similar vein, $[34,16]$ demonstrate that consultative devices are conventionalized in western culture, which is not in line with the Greek culture. Reference [40] relates the sparing use of consultative devices to [13] notions of negative and positive politeness. Greek culture concentrates on in-group nexus and solidarity, which are characteristic of positive politeness. This is opposite to individualistic culture, which focuses on indirectness and tact, and where consultative devices are noted to function with negative politeness strategies. However, examples of the lexical downgraders are presented below:

Politeness marker:

From: Learner's e-mail

Date: Tue, May 12, 2015 at 9:50 PM

Subject: meeting

To: Professor's e-mail

Dear Dr. (X)

Please give me another meeting because I can't come.

Yours,

Hedged downtoner:

From: Learner's e-mail 
Date: Sat, Jun 7, 2015 at 12:11 AM

Subject: my assignment

To: Professor's e-mail

Alsalam Alaikom

I'm kindly asking for another meeting.

Your student,

Subjectivizer:

From: Learner's e-mail

Date: Tue, Jul 21, 2015 at 7:10 PM

Subject: need ur comment

To: Professor's e-mail

Good evening, Dr. (X)

I'm wondering if you can give me your comment on my proposal.

Consultative devices:

From: Learner's e-mail

Date: Fri, Jun 19, 2015 at 9:11 PM

Subject:

To: Professor's e-mail

Is it alright if I come this Monday?

Salam

Strikingly, after a closer examination of Tables 5 and 6, it seems that Iraqi EFL learners have used more syntactic downgraders than lexical devices in their requests. This is due to the structurally oriented approach employed in Iraq. Such an approach focuses on the grammatical aspects of language. Hence, Iraqi EFL learners have control in using syntactic downgraders but show pragmatic deficiency in the use of lexical downgraders. Iraqi EFL learners have not yet acquired the pragmatic function of lexical downgraders and therefore they have compensated for that lack by using syntactic downgraders.

The result regarding internal modifications is in line with the findings of previous studies. For instance, [17] unveiled that EFL learners had pragmatic deficiency in the lexical downgraders. Also, [8] uncovered that native speakers of English tended to use more syntactic downgraders in their requests. In addition, [32] revealed that native speakers of English remarkably preferred to use more syntactic downgraders in requesting than Chinese learners of English.

\section{Conclusion}

This study concludes that Iraqi EFL learners face difficulties in issuing appropriate requests via email. These learners have pragmalinguistic deficiency in producing academic requests to their professors. They tend to use more direct strategies due to the influence of their L1 and culture. On the other hand, they use conventional indirectness sparingly because they have limited pragmalinguistic knowledge of it. Yet, these learners implement a range of syntactic devices to tone down the impositive tone of their requests. On the other hand, they are not acquainted with the pragmatic functions of the lexical downgraders which cause pragmatic infelicity in their production.

In addition, Iraqi EFL learners have limited opportunities for obtaining L2 input. They learn English in their EFL setting which does not provide adequate chances for developing their pragmatic abilities. 


\section{References}

Abdul Sattar, H. Q., Lah, S. C., \& Suleiman, R. R. R. (2009). Iraqi postgraduates' production and perception of requests: A pilot study. The International Journal of Language Society and Culture, 29, 56-70.

Aijmer, K. (1996). Conversational Routines in English. London: Longman.

Aldhulaee, M. T. (2011). Request mitigating devices in Australian English and Iraqi Arabic: A comparative study (Master thesis). Retrieved August 17, 2015 from https://dro.deakin.edu.au/eserv/DU:30052041/aldhulaee-requestmitigating-2011.pdf.

Al-Momani, H. S. (2009). Caught between two cultures: The realization of requests by Jordanian EFL learners (Doctoral dissertation). Retrieved May 20, 2015 from http://dspace.iup.edu/bitstream/handle/2069/176/Husam\%20Al-Momani.pdf?sequence=1.

Al-Zubaidi, N. (2012). Expressions of gratitude in American English and Iraqi Arabic. Interlanguage and cross-cultural pragmatics perspectives. Deutschland,Germany: Lambert Academic Publishing.

Barron, A. (2003). Acquisition in interlanguage pragmatics. Learning how to do things with words in a study abroad context. Philadelphia, USA: John Benjamins Publishing Company.

Beebe, L. M., \& Cummings, M. C. (1996). Natural speech act data versus written questionnaire data: How data collection method affects speech act performance. In S. M. Gass \& J. Neu (Eds.), Speech acts across cultures: Challenges to communication in a second language (pp. 65-86). Berlin: Mouton de Gruyter.

Biesenbach-Lucas, S. (2007). Students writing emails to faculty: An examination of e-politeness among native and non-native speakers of English. Language Learning \&Technology, 11(2), 59-81.

Blum-Kulka, S. (1987). Indirectness and politeness in requests: Same or different? Journal of Pragmatics, 11,131-146.

Blum-Kulka, S., \& Olshtain, E. (1984). Requests and apologies: A cross-cultural study of speech act realization patterns (CCSARP). Applied Linguistics, 5(3), 196-213.

Blum-Kulka, S., \& Olshtain, E. (1986). Too many words: Length of utterance and pragmatic failure. Studies in Second Language Acquisition, 8(02), 165-179.

Blum-Kulka, S., House, J., \& Kasper, G. (1989). Cross-cultural pragmatics: Requests and apologies. Norwood, NJ: Ablex.

Brown, P., \& Levinson, S. C. (1987). Politeness: Some universals in language usage (Vol. 4). Cambridge: Cambridge University Press.

Chen. C. E. (2006). The development of e-mail literacy: From writing to peers to writing to authority Tables. Language Learning \& Technology, 10(2), 35-55.

Creswell, J. W. (2012). Educational research: Planning, conducting, and evaluating quantitative and qualitative research $\left(4^{\text {th }}\right.$ Edition). New York: Pearson Education. 
Economidou-Kogetsidis, M. (2008). Internal and external mitigation in interlanguage request production: The case of Greek learners of English. Journal of Politeness Research, 4(1), 111138.

Economidou-Kogetsidis, M. (2011). Please answer me as soon as possible: Pragmatic failure in nonnative speakers' e-mail requests to faculty. Journal of Pragmatics, 43(13), 3193-3215.

Economidou-Kogetsidis, M. (2012). Modifying oral requests in a foreign language: The case of Greek Cypriot learners of English. In M. Economidou-Kogetsidis \& H. Woodfield (Eds.), Interlaguage request modification (pp. 163-202). Philadelphia, USA: John Benjamins Publishing Company.

Ellis, R. (1994). The study of second language acquisition. Oxford: Oxford University Press.

Faerch, C., \& Kasper, G. (1989). Internal and external modification in interlanguage request realization. In Blum-Kulka, S., House, J., \& Kasper, G. (Eds.), Cross-cultural pragmatics: Requests and Apologies (pp. 221-247). Norwood, NJ: Ablex.

Gaskell, G. \& Bauer, M. (2000). Towards public accountability: Beyond sampling, reliability and validity. In M. W. Bauer \& G. Gaskell (Eds.), Qualitative researching with text, image and sound (pp. 336-350). London: Sage.

Hartford, B. S., \& Bardovi-Harlig, K. (1996). At your earliest convenience: A study of written student requests to faculty. In L. F. Bouton (Ed.), Pragmatics and language learning (Vol.7, pp. 5569). Urbana-Champaign: Division of English as an International Language.

Hassall, T. (2003). Requests by Australian learners of Indonesian. Journal of Pragmatics, 35(12), 1903-1928.

Hassall, T. (2012). Request modification by Australian learners of Indonesian. In M. EconomidouKogetsidis \& H. Woodfield (Eds.), Interlanguage request modification (pp. 203-242). Philadelphia, USA: John Benjamins Publishing Company.

Haugh, M. (2007). The discursive challenge to politeness research: An interactional alternative. Journal of Politeness Research, 3 (2), 295-317.

House, J., \& Kasper, G. (1987). Interlanguage pragmatics: Requesting in a foreign language. In W. Lörscher \& R. Schulze (Eds.), Perspectives on language in performance (pp. 1250-1288). Tübingen: Narr.

Kasper, G. (1992). Pragmatic transfer. Second Language Research, 8(3), 203-231.

Locher, M. A., \& Watts, R. J. (2005). Politeness theory and relational work. Journal of Politeness Research, 1(1), 9-33.

Meyer, C. (2002) English corpus linguistics: An introduction. Cambridge: Cambridge University Press.

Najeeb, Z. M., Maros, M., \& Nor, N. F. M. (2012). Politeness in e-mails of Arab students in Malaysia. GEMA: Online Journal of Language Studies, 12(1),125-145.

Olshtain, E. \& Cohen, A. (1983). Apology: A speech act set. In N. Wolfson, \& E. Judd (Eds.), Sociolinguistics and language acquisition (pp. 18-36). Rowley,MA: Newbury House. 
Pan, P. C. (2012). Interlanguage requests in institutional e-mail discourse: A study in Hong Kong. In M. Economidou-Kogetsidis \& H. Woodfield (Eds.), Interlaguage request modification (pp. 119-162). Philadelphia, USA: John Benjamins Publishing Company.

Schauer, G. A. (2009). Interlanguage pragmatic development: The study abroad context. London: Continuum International Publishing Group.

Sifianou, M. (1992). Politeness Phenomena in England and Greece: A Cross-cultural Perspective. Clarendon Press, Oxford.

Soler, E. A. (2013). Pragmatic variation in British and International English language users' e-mail communication: A focus on requests. Revista Española de Lingüística Aplicada, (26), 25-44.

Trosborg, A. (1995). Interlanguage pragmatics: Requests, complaints, and apologies. Berlin: Mouton de Gruyter.

Umar, A. A. (2004). Request strategies as used by advanced Arab learners of English as a foreign language. Umm Al-Qura University Journal of Educational \& Social Sciences \& Humanities, $16(1), 42-87$.

Woodfield, H. (2008). Interlanguage requests: A contrastive study. In M. Pütz \& J. N. Aertselaer (Eds.), Developing contrastive pragmatics. Interlanguage and cross-cultural perspectives (pp. 231-264). Berlin: Mouton de Gruyter.

Woodfield, H. (2012). "I think maybe I want to lend the notes from you". Development of request modification in graduate learners. In M. Economidou-Kogetsidis \& H. Woodfield (Eds.), Interlanguage request modification (pp. 9-50). Philadelphia, USA: John Benjamins Publishing Company.

Woodfield, H., \& Economidou-Kogetsidis, M. (2010). 'I just need more time': A study of native and non-native students' requests to faculty for an extension. Multilingua, 29(1), 77-118.

Wouk, F. (2006). The language of apologizing in Lombok, Indonesia. Journal of Pragmatics, 38(9), 1457-1486. 
(Tables \& Figures)

Table 1: Request Strategies

\begin{tabular}{lc}
\hline \hline Type of strategy & Percentage \\
\hline Direct & $50 \%$ \\
Conventional indirect & $29 \%$ \\
Nonconventional & $21 \%$ \\
indirect & \\
\hline \hline
\end{tabular}

Table 2: Direct Sub-strategies

\begin{tabular}{cc}
\hline \hline Type of strategy & Percentage (No./total) \\
\hline Mood derivable & $17 \%(10 / 60)$ \\
Explicit performative & $8 \%(5 / 60)$ \\
Hedged performative & $22 \%(13 / 60)$ \\
Locution derivable & $1.5 \%(1 / 60)$ \\
Want statement & $42 \%(25 / 60)$ \\
Need statement & $3.3 \%(2 / 60)$ \\
Direct question & $3.3 \%(2 / 60)$ \\
Expectation statement & $3.3 \%(2 / 60)$ \\
\hline \hline
\end{tabular}

Table 3: Conventional Indirect Sub-strategies

\begin{tabular}{cc}
\hline \hline Type of strategy & Percentage (No/total) \\
\hline Suggestory formulae & $2.8 \%(1 / 35)$ \\
QP/Ability & $22.8 \%(8 / 35)$ \\
QP/Permission & $42.8 \%(15 / 35)$ \\
QP/Possibility & $2.8 \%(1 / 35)$ \\
QP/Willingness & $5.7 \%(2 / 35)$ \\
QP/Mitigated Preparatory & $22.8 \%(8 / 35)$ \\
\hline \hline
\end{tabular}


Table 4: Nonconventional Indirect Sub-Strategies

\begin{tabular}{cc}
\hline \hline Type of strategy & Percentage (No/total) \\
\hline Hints & $80 \%(20 / 25)$ \\
Nonverbal request & $20 \%(5 / 25)$ \\
\hline \hline
\end{tabular}

Table 5: Syntactic Downgraders

\begin{tabular}{cc}
\hline \hline Type of modifier & Percentage (No/total) \\
\hline Interrogative & $6 \%(9 / 150)$ \\
Conditionals & $38.7 \%(58 / 150)$ \\
Aspect & $2 \%(3 / 150)$ \\
Tense & $20 \%(30 / 150)$ \\
Embedding & $33.3 \%(50 / 150)$ \\
\hline \hline
\end{tabular}

Table 6: Lexical Downgraders

\begin{tabular}{cc}
\hline \hline Type of modifier & Percentage (No/total) \\
\hline Politeness marker & $60 \%(30 / 50)$ \\
Hedged downtoner & $24 \%(12 / 50)$ \\
Subjectivizer & $12 \%(6 / 50)$ \\
Consultative devices & $4 \%(2 / 50)$ \\
\hline \hline
\end{tabular}

